\title{
Research Paper: The Role of Internalizing and Externalizing Symptoms and Social Isolation in Teenage Girls Towards the Use of Internet and Cyberspace
}

\author{
Mahtab Esmaeilzadeh Azad ${ }^{1} \mathbb{C}$, Mahdi Amini $^{2^{*}} \mathbb{C}$, Mozhgan Lotfi $^{3}$ \\ 1. Department of Counseling, Faculty of Literature Humanities and Social Sciences, Science and Research Branch, Islamic Azad University, Tehran, \\ Iran. \\ 2. Department of Addiction, School of Behavioral Sciences and Mental Health (Tehran Institute of Psychiatry), Iran University of Medical Sciences, \\ Tehran, Iran. \\ 3. Department of Mental Health, School of Behavioral Sciences and Mental Health (Tehran Institute of Psychiatry), Iran University of Medical Sciences \\ Tehran, Iran.
}

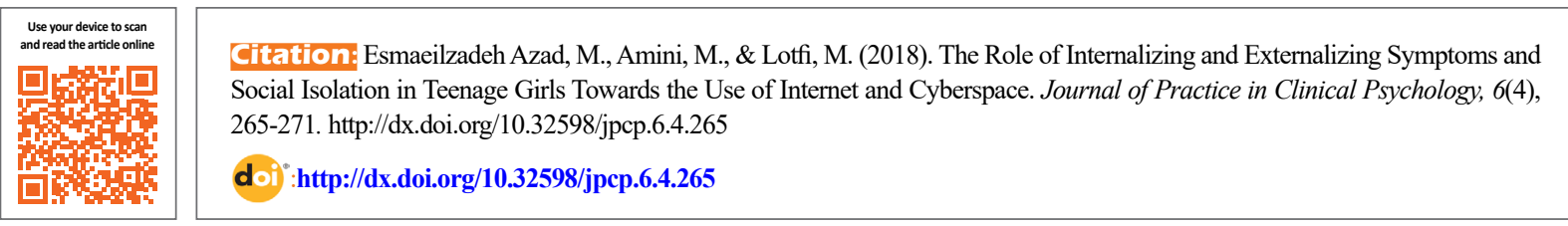

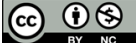

Funding: See Page 270

Article info:

Received: 15 Mar 2018

Accepted: 23 Aug 2018

Available Online: 01 Oct 2018

Keywords:

Internet addiction,

Externalizing symptoms, Internalizing symptoms, Social isolation

\section{ABSTRACT}

Objective: The current study was conducted to investigate the role of internalizing and externalizing symptoms and social isolation due to Internet addiction and cyberspace use among teenage girls in 2016-2017 year.

Methods: The research method used in this study was cross-sectional. The study population included all girl students of the second grade public high schools of Tehran city during the academic year 2016-2017. Based on multi-stage cluster sampling, 300 girls were selected randomly. The tools used for data collection were Russell's loneliness scale, Young's Internet addiction test, and Achenbach's self-report questionnaire. Finally, the collected data was analyzed using SPSS v.20 software using Pearson's correlation coefficient and regression analysis.

Results: The results showed that there is a positive and significant relationship of internalized syndrome $(\mathrm{r}=0.53)$, extraversion syndrome $(\mathrm{r}=0.57)$, and social isolation $(\mathrm{r}=0.54)$, with internet addiction. Regression test showed that seizure syndrome, thinking syndrome among internalized syndromes, obsessive compulsive syndrome, other problems, favorable conditions, outbreak law, problems of disorder among extraversion syndromes and social isolation had the most impact on the variability of Internet addiction.

Conclusion: The results of this study showed that individuals with internalized and externalized symptoms and girls who are socially isolated tend to have more Internet and virtual space addiction.

\section{* Corresponding Author:}

Mahdi Amini, PhD

Address: Department of Addiction, School of Behavioral Sciences and Mental Health (Tehran Institute of Psychiatry), Iran University of Medical Sciences, Tehran, Iran.

Tel: +98 (912) 9493724

E-mail: amini.mh@iums.ac.ir 


\section{Highlights}

- Internalizing and externalizing symptoms and social isolation result in teenage girls' excessive use of the Internet addiction and cyberspace.

- There is a positive and significant relationship between internalized syndrome, extraversion syndrome, and social isolation, with the Internet addiction.

- Based on our study results individuals with internalized and externalized symptoms and girls who are socially isolated tend to use more the Internet and virtual space.

\section{Plain Language Summary}

The current study examined the effect of internalizing and externalizing symptoms and social isolation on the Internet addiction and cyberspace use among Iranian teenage girls. The research design was cross-sectional. All high school girl students of the second grade in public schools of Tehran City during the academic year 2016-2017 were study population. Based on multi-stage cluster sampling, 300 girls were selected randomly. The relevant data were collected by Russell's loneliness scale, Young's Internet addiction test, and Achenbach's self-report questionnaire and were analyzed in SPSS V. 20 using Pearson and regression tests. The results showed a positive and significant relationship between internalized syndrome, extraversion syndrome, and social isolation, with the Internet addiction. Therefore, individuals with internalized and externalized symptoms and girls who are socially isolated tend to use more the Internet and virtual space.

\section{Introduction}

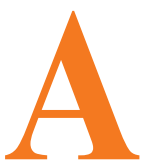

dolescence is considered as the transitional stage from childhood to adulthood, which comes with a wide range of changes in physical, psychological and social dimensions (Cheng \& Cheng, 2015). It is one of the most critical periods in life that is subject to various factors such as family, peers, school and social networks in terms of growth and performance in various internal and interpersonal dimensions (Balakrishnan, 2015). Facilitation in the access to social networks and the Internet, and the necessity of access to the internet for managing daily routine, has led to the transformation of the present phenomenon into a vital part of people's lives and has increased the number of the users (Dillon \& Bushman, 2015). The growing complications of Internet addiction have led to the disruption of the order, and are topical to all behavioral addictions (Hamidian, 2000). This disorder is an interdisciplinary phenomenon which covers various medical, computer, sociological, law, ethical and psychological sciences; different dimensions of each if this phenomenon has been studied (Moidfar, Habbibpoor, \& Ganji, 2008). Despite all the benefits of the Internet to today's human, this modern communication technology is a double-edged sword that has many disadvantages and problems, especially for the younger generation. Adolescents tend to exploit this phenomenon under the influence of various internal, interpersonal and even environmental factors, social isolation and, internalized and internalized symptoms are its most important factors (Kubiszewski, Fontaine, Potard, \& Auzoult, 2015).

Externalizing problems are symptoms that are in conflict with other people and their expectations, and the extent of its harmful effects on others is more than that of the individual itself. The internalized symptoms cause more self-harm than harming others, their core being mood (affective) disorder (Lee, Zhou, Ly, Main, Tao, \& Chen, 2014). Clinical studies suggest that internalizing symptoms have a significant impact on the use of cyberspace and social networks in children and adolescents (Satoorian, Haratian, Tahmassian, \& Ahmadi, 2016). Yoo et al. (2004), Sheldon (2008), in separate studies, indicated that individuals with externalized and internalized symptoms are more likely to get inclined towards social networks and virtual communication spaces. Internet addiction is much higher among this group (Griffiths, Kuss, \& Demetrovics, 2014).

Social isolation is one of the other factors influencing an adolescent's inclination towards cyberspace and social networks (Nourian Aghdam, Almardani Some'eh, \& Kazemi, 2016). Social isolation is the lack of an individual's interest in engaging in activities and social rela- 
tionships in the real environment, and it their tendency to remain in seclusion and loneliness (Kuss \& Griffiths, 2017). It is one of the destructive consequences of using cyberspace and the most important cause of the inclination towards cyberspace use. Many researches have emphasized its relationship with teenagers and their inclination towards cyberspace and social networks (Choupani, Karimnejhad, \& Farahbakhsh, 2017). Kamkar, Bagheri-zadeh Moqadam, \& Manouchehri (2013), Morahan Martin and Schumacher (2000) also pointed out in their research that teenagers and the young Internet users were more intimately attached than those who did not use this tool, and the amount of social isolation and the distance from the family and the family environment was higher than others. Research shows that for every hour of using the Internet at home, half an hour of direct communication with family members is reduced, and this escape into an open and networked society leads them away from the community (Motamednejad, 2002). Growing volumes of research on Internet addiction suggests that this disorder is a psycho-social disorder, characterized by tolerance, withdrawal symptoms, emotional disturbances, and disruption of social relationships (Feriis, 2002).

The aforementioned information has shown a high increase in adolescents' inclination towards cyberspace and social networks, high increase in psychological and social harm caused by Internet addiction in this age group. This necessitates the identification of influential factors that attract adolescents to cyberspace, and to develop preventive, educational and therapeutic programs in this area. A review of literature highlighted that not much was known about the role of internalization and externalization syndromes and social isolation on Internet inclination and cybercrime in adolescent girls, so this research was aimed at removing the vacuum in this field. This research was conducted to define how comprehensive is the role of social isolation and internalization and externalization symptoms in the increased inclination of the teenage girls towards cyberspace. The results ob- tained, to some extent, could be effective in formulating and implementing the mentioned programs.

\section{Methods}

This study was cross-sectional. The study population consisted of girls from public high schools (second grade) of Tehran during the academic year 2016-2017. The sampling method used was randomized multistage cluster sampling. First of all, from the 22 districts of Tehran, the sixth district was selected randomly; then, from the schools of the sixth district, five girls school in the second grade were randomly selected, and from each school, 50 students responded to the research questionnaires. A total of 300 students participated in this study. Data was collected randomly. Along with the ethical considerations, the inclusion criteria were a girl who is a high school student, age range of 15 to 18 years, while exclusion criteria required a particular physical and mental condition, unwillingness in participation in this research. Participation was with the individual's consent, and all of them responded to the questionnaires willingly. The confidentiality of information was assured. To this end, it was not mandatory to write the participant's name; only age was enough. The collected data were analyzed in SPSS v.20 statistical software using descriptive and inferential statistics, Kolmogorov-Smirnov test for data normalization, Pearson's correlation coefficient, regression analysis and independent t-test. The instruments used in the current study for data collection are as following:

UCLA (University of California, Los Angeles) Loneliness Scale which was compiled by Russell, Pilva, and Cortino (2000) containing 20 quadrants, 10 negative sentences, and 10 positive sentences and the answers were based on 4-point Likert scale as "1=never", "2=rarely", " $3=$ sometimes", and " $4=$ often". The reliability of this test was reported to be $89 \%$. Shekarkan and Mirderikvand (2008) translated the scale and emphasized on its reli-

Table 1. Pearson correlation coefficient between internet addiction, social isolation, internalized and externalized symptoms

\begin{tabular}{|c|c|c|c|c|}
\hline Variables & Internet Addiction & Social Isolation & Internalized Symptoms & Externalized Symptoms \\
\hline Internet addiction & 1 & & & \\
\hline Social isolation & $0.54 * *$ & 1 & & \\
\hline Internalized symptoms & $0.53^{* *}$ & $0.68^{* *}$ & 1 & \\
\hline Externalized symptoms & $0.58 * *$ & $0.54 * *$ & $0.57 * *$ & 1 \\
\hline
\end{tabular}


Table 2. Regression test results for the impact of social isolation, externalized syndrome, and internalized syndrome on internet addiction

\begin{tabular}{ccccc}
\hline Model & $\mathbf{R}$ & $\mathbf{R}^{2}$ & Adjusted $\mathbf{R}^{2}$ & Standard Error of the Estimate \\
\hline 1 & 0.648 & 0.42 & 0.414 & 3.63 \\
\hline
\end{tabular}

ability and validity. The reliability of this questionnaire in the present study was 0.76 using Cronbach's alpha.

Another tool is the Young's Internet Addiction Test (IAT) which was developed by Young in 1988 to evaluate the Internet addiction of individuals. The test was designed in 20 items and was based on a 6-point Likert scale $(0=$ No time, $1=$ rarely, $2=$ occasional, $3=$ many times, 4=often, 5=always) (Alavi et al., 2010). The scores for each person will categorize him into either of the below mentioned three categories: 1. Average user of the Internet (score 20-49); 2. User who has been in many difficulties (score 50-79); 3. Addicted person who has an excessive dependence to the Internet, and needs treatment (score 80-100). Young (1988) reported the reliability of this test to be $92 \%$ and reported that its reliability is a re-test. Alavi et al. (2010) reported the reliability of the questionnaire using Cronbach's alpha to be 0.88 . The reliability of this questionnaire was 0.85 using Cronbach's alpha.

Another surveying tool used in this study is Youth Self-Report (YSR) which was developed by Thomas M. Achenbach in 1991, and is used for people aged 1118 with the minimum of fifth grade educational level. It should be filled in 15 minutes (Habibi Asgarabad et al., 2009). This scale includes two sections of competencies and symptoms. The symptoms section includes 112 items such as depression/isolation, physical complaint, depression/anxiety, social problems, thinking problems, attention problems, delinquent behaviors, aggressive behaviors, and other behavioral problems. The correlation coefficient of this scale was reported to be 39.68 to 68.00 using the Eysenck personality questionnaire. Zargar, Bahramabadi and Besaknejad (2012) also reported that the reliability of this questionnaire is $91 \%$. The reliability of this questionnaire was 0.82 using Cronbach's alpha.

\section{Results}

From the 300 participants in the study, 57(19\%) are in the age group of $15,93(31 \%)$ are in the age group of $16,73(24 \%)$ are in the age group of 17 , and $77(26 \%)$ of them are in the age group of 18 . Here, the Pearson correlation and regression results are given. Pearson's correlation coefficient was used to investigate the relationship between research variables as shown in Table 1.

The results of Pearson's correlation coefficient showed that internalized symptoms, externalized symptoms and social isolation have a positive and significant relationship with Internet addiction and cyberspace. In order to investigate the role of predictor variables, step by step regression was used.

Table 2 shows regression test results for the impact of social isolation, externalized syndrome, and internalized syndrome on Internet addiction. The correlation coefficient of the model is 0.648 ; in other words, there was a significant relationship between the components and the inclination towards use of Internet. The value of $\mathrm{R}^{2}$ indicates that $42 \%$ of the changes in Internet addiction were due to the effects of social isolation variables, externalized symptoms, and internalized symptoms (Table 2).

Table 3. Regression results to predict internet addiction based on independent variables

\begin{tabular}{|c|c|c|c|c|c|}
\hline \multirow{2}{*}{ Model } & \multicolumn{2}{|c|}{ Standardized Coefficients } & \multirow{2}{*}{$\begin{array}{c}\text { Unstandardized Coefficients } \\
\text { Beta }\end{array}$} & \multirow{2}{*}{$\mathbf{T}$} & \multirow{2}{*}{ Sig. } \\
\hline & B & Standard Error & & & \\
\hline Stable & 13.04 & 2.60 & & 4.99 & 0.000 \\
\hline Internalized symptoms & 0.119 & 0.045 & 0.170 & 2.65 & 0.008 \\
\hline Externalized symptoms & 0.141 & 0.022 & 0.353 & 6.30 & 0.000 \\
\hline Social isolation & 0.220 & 0.059 & 0.234 & 3.75 & 0.000 \\
\hline
\end{tabular}


The obtained $\mathrm{F}$ value (71.331) was significant $(\mathrm{P}<0.01)$, and showed that the variables are independent of the high correlation power and can explain the variation and variance of the dependent variable well.

In Table 3, the standardized and unstandardized coefficients, the t-test and the significance level of predictive variables for predicting internet addiction are presented. The results of Pearson's correlation coefficient showed that there was a positive and significant correlation between the internalized symptoms and Internet addiction, with a correlation coefficient of 0.53 . Also, all subscales of internalized symptoms have a positive and significant relationship with Internet addiction, at the level $\mathrm{P} \leq 0.05$. Regression test showed that seizure syndrome, thinking syndrome among internalized syndromes, obsessive compulsive syndrome, other problems, favorable conditions, outbreak law, problems of disorder among extraversion syndromes and social isolation had the most impact on the variability of Internet addiction.

\section{Discussion}

The main goal of this study was to investigate the role of internalized and externalized symptoms and social isolation on the level of inclination towards the use of Internet and cyberspace in teenage girls. Internalized symptoms involve problems such as anxiety, discomfort in social skills, confusion, problems in which an individual does not have the ability to deal with the external world, or if he or she does not have the ability to deal the fear that comes with it, a kind of fear that to a large extent leads to social avoidance and resort to the inner and virtual world, which would make the non-attending formation and continuity of communication and social interactions possible for her.

In fact, many people, especially with the internalized symptoms, under the effect of various causes and factors such as fear of entering the real community, the desire for social isolation, and the lack of adequate social communication skills deprive themselves of the pleasure of entering the social world (Vatani et al., 2015). But because human beings have a social nature, and every human being tends to establish relationships with others in various emotional-sexual forms, this group provides such pleasures for themselves through social networks by establishing virtual and unrealistic communication with familiar and unfamiliar people. They abstain from their true selves - the need of communication with the outside world - and drown themselves in the virtual and unreal world.
The results of this study showed that internalized and externalized symptoms and social isolation have a significant effect on the rate of inclination towards the use of the Internet and cyberspace in adolescent girls and to a large extent predicts this inclination. Concerning the internalized symptoms variable and its role in directing adolescent girls into cyberspace and social networks, the results of the research indicate that this variable significantly and largely predicts the inclination of adolescent girls to cyberspace and social networks. McGrath and Vanugott (2009) and Sheldon (2008) also showed in their study that the internalized symptoms variable, in a general form, has a significant and essential role in predicting the inclination of adolescent girls to social networks and increases the probability of the inclinations towards networking among the group. Satoorian et al. (2016) reported in their research that the externalized symptoms, while having a devastating effect on the functional health of children and their relatives, also have a significant effect on increasing the probability of children and adolescent's inclination to cyberspace and social networks as well.

Yoo et al. (2004) also showed that people with the externalized symptoms, such as hyperactivity and Attention Deficit Hyperactivity Disorder (ADHD), have a higher inclination toward social networking and virtual communication space compared to normal people. Internet addiction is much higher in this group. In this study, social isolation showed a positive and significant relationship with the inclination of adolescent girls to social networking, which largely predicts this inclination. Choupani, Karimnejhad, \& Farahbakhsh (2017) reported that the role of social isolation has been emphasized as one of the main causes of the adolescent inclination to cyberspace and social networks. Martin and Schumacher (Morahan-Martin \& Schumacher, 2000) also concluded that teenagers enjoying social isolation use cyberspace and social networks more than normal teenagers.

The second hypothesis of the study was to investigate the relationship between the internalized symptoms and all its subscales and the adolescent girls' inclination to Internet and cyberspace, and the results showed there is a significant and positive relationship. In fact, the results of the data analysis showed that between the internalized symptoms subscales including anxiety, depression, physical complaints, social problems, thought disorders, ADHD and the extent of the adolescent inclination towards the Internet and the cyberspace there is a significant and positive relationship. Previous researches had examined these subscales in their studies and have identified them as one of the most important factors in the 
inclination towards the Internet and cyberspace. Anari et al. (2015), Vatani et al. (2015) each in separate studies explored the internalized symptoms and its components and declared a positive and significant relationship with the inclination to cyberspace.

Another research hypothesis was related to externalized symptoms and their components and also the rate of inclination towards the Internet and cyberspace. It has been shown in this study that there is a positive and significant relationship between the externalized symptoms and all its subscales, and the rate of teenage girls' inclination towards the Internet and cyberspace. Also, the individual subscales of these symptoms including lawbreaking, aggression, other problems, obsessive-compulsive disorder, disorder problems, and ideal condition were studied, and the results of the data analysis indicated a significant positive relationship. Yoo et al. (2004) and Vatani et al. (2015) examined the internalized and externalized symptoms and the main factors involved in the inclination towards Internet and cyberspace and achieved similar results.

In the last research hypothesis, the relationship between social isolation and inclination to the Internet and cyberspace (social networking) was studied. The results of data analysis indicated that there is a positive and significant relationship between variables. Nourian-aghdam et al. (2016) emphasized in their research that isolation is one of the main causes of adolescents' inclination towards virtual and social networks, and those who have this sign, compared to normal people, are more likely to have an inclination towards the Internet and cyberspace (social networks). Kamkar et al. (2016); Rabei and Mohammadzade (2013) are other researchers who emphasized the positive and significant relationship between social isolation and the amount of inclination towards the Internet and cyberspace, also indicated that the frequency and the amount of cyberspace use by people with social isolation is much higher compared to normal people. Everyone has a tendency towards having a social relationship, a desire that if not granted, would lead to a range of interpersonal and intrapersonal dissatisfactions. However, many people affected by their intrinsic imperfections lack the ability to establish such relationships, including those with social isolation.

The lack of attention to the male gender is one of the limitations of this research, which is suggested to be used in further research in order to better boys' generalization. Also, based on causal inference and assessment of the effectiveness of different patterns and therapeutic approaches on internalized, transmitted, and social isola- tion, it is recommended to conduct experimental studies and research on their role in reducing students' tendency to use social networks.

People, especially with internalized, externalized symptoms and social isolation, are socially affected by causes and factors such as fear of entering the real community, the desire for social isolation and lack of enough communication and social skills due to which they deprive themselves of the pleasure of entering the social world. Because humans are inherently social beings, every human being tends to establish relationships with others in various emotional-sexual forms. This group by retrieving social networks provides such pleasure to oneself. By establishing virtual connections with people, both familiar and strangers, they refuse to recognize their true self that requires interaction with the outside world and drown themselves in a virtual and unreal world.

\section{Ethical Considerations}

\section{Compliance with ethical guidelines}

Participation was with the individual's consent, and all of them responded to the questionnaires willingly. The confidentiality of information was assured. To this end, it was not mandatory to write the participant's name; only age was enough.

\section{Funding}

This article is the result of a MSc. thesis of Mahtab Esmaeilzadeh Azad in Department of Counseling, Science and Research Branch, Islamic Azad University and does not have sponsor.

\section{Conflict of interest}

The authors declared no conflict of interest.

\section{Acknowledgments}

The authors thank and appreciate the management and affiliated public schools of Tehran, the girl students of the high schools for participating in this research and those who helped with this research.

\section{References}

Alavi, S., Eslami, M., Maracy, M., Najafi, M., Jannatifard, F., \& Vezapour, H. (2010) . [Psychometric properties of young in- 
ternet addiction test (Persian)]. Journal of Behavioral Sciences, 4(3):183-9.

Anari, M., Mazaheri Tehrani, M., \& Tahmasebian, K. (2015). [life satisfaction, internalizing and externalizing disorders in social networks users and non-users (Persian)]. Strategy for Culture, 7(27), 120-137.

Balakrishnan, V. (2015). Cyberbullying among young adults in Malaysia: The roles of gender, age and Internet frequency. Computers in Human Behavior, 46, 149-57. [DOI:10.1016/j. chb.2015.01.021]

Cheng, P. F., \& Cheng, C. H. (2015). Effects of Moral Self, Self Esteem and Parental Bonding on Delinquency among Young People in Hong Kong. International Journal of Criminology and sociology, 4, 119-27. [DOI:10.6000/1929-4409.2015.04.12]

Choupani, M., Karimnejhad, K., \& Farahbakhsh, K. (2017). [The study of personality characteristics of male infidelity: A qualitative study (Persian)]. Personality Quarterly and Individual Differences, 5(13), 87-105.

Dalbudak, E., \& Evren, C. (2014). The relationship of Internet addiction severity with Attention Deficit Hyperactivity Disorder symptoms in Turkish University students; impact of personality traits, depression and anxiety. Comprehensive Psychiatry, 55(3), 497-503. [DOI:10.1016/j.comppsych.2013.11.018] [PMID]

Dillon, K. P., \& Bushman, B. J. (2015). Unresponsive or un-noticed? Cyberbystander intervention in an experimental cyberbullying context. Computers in Human Behavior, 45, 144-150. [DOI:10.1016/j.chb.2014.12.009]

Ferris, J. R. (2002). Internet addiction disorder: Causes, symptoms, and consequences [Intrnet]. Retrieved from https://netaddictionrecovery.com/the-problem/internet-addiction/208-internet-addiction-disorder-causessymptomsand-consequences.html

Griffiths, M. D., Kuss, D. J., \& Demetrovics, Z. (2014). Social networking addiction: An overview of preliminary findings. In K. P. Rosenberg, L. C. Feder (Eds.). Behavioral Addictions: Criteria, Evidence, and Treatment (pp. 119-141). New York: Elsevier. [DOI:10.1016/B978-0-12-407724-9.00006-9]

Habibi-Asgarabad, M., Besharat, M., Fadaei, Z., Najafi, M. (2009). [Confimatory factorial structure, reliability and validity of the Achenbach Youth Self-Report Scale (YSR): Monozygotic and dyzigotic twins (Persian)]. Journal of Clinical Psychology, 1(1):1-18.

Hamidian, F. (2000). [Addiction to the Internet and mobile: Evaluation of complications related to the Internet, mobile and PC games (Persian)]. Tehran: Ghatreh.

Kamkar, H., Bagherizadeh Moghaddam, F., \& Manochehri, A. (2013). Feelings of loneliness and internet addiction in adolescence. Paper presented at The $6^{\text {th }}$ International Congress on Child and Adolescent Psychiatry, Tabriz, Iran, 17-19 September 2013.

Kubiszewski, V., Fontaine, R., Potard, C., \& Auzoult, L. (2015). Does cyberbullying overlap with school bullying when taking modality of involvement into account? Computers in $\mathrm{Hu}$ man Behavior, 43, 49-57. [DOI:10.1016/j.chb.2014.10.049]

Kuss, D. J., \& Griffiths, M. D. (2017). Social networking sites and addiction: Ten lessons learned. International Journal of Envi- ronmental Research and Public Health, 14(3), 311. [DOI:10.3390/ ijerph14030311] [PMID] [PMCID]

Lee, E. H., Zhou, Q., Ly, J., Main, A., Tao, A., \& Chen, S. H. (2014). Neighborhood characteristics, parenting styles, and children's behavioral problems in Chinese American immigrant families. Cultural Diversity and Ethnic Minority Psychology, 20(2), 202. [DOI:10.1037/a0034390] [PMID]

Macgrath M., \& Vanvugt, J. (2009). Young People and technology: A review of current literature. Melbourne: Alannah and Madeline Foundation.

Morahan-Martin, J., \& Schumacher, P. (2000). Incidence and correlates of pathological Internet use among college students. Computers in Human Behavior, 16(1), 13-29. [DOI:10.1016/ s0747-5632(99)00049-7]

Mohammadijou A. (2013). [Role of the internet on social isolation among students of Islamic Azad University in Tehran center 92 (Persian)]. Media Studies, 8(22), 19-30.

Moidfar, S., Habbibpoor, G. K., Ganji, A. (2008). [Study of addictive Internet among adolescent and young (15-25 years) in Tehran (Persian)]. Retrived from: http:/ / gmj.ut.ac.ir/Attachments/2012821163934897.pdf

Motamednejad, K. (2002). [UNESCO and the protection of children against Internet (Persian)]. Resaneh Journal, 12(2), 28-33.

Nourian Aghdam, J., Almardani Some'eh, S., \& Kazemi, R. (2016). [Comparison of sleep disturbance, social isolation and emotion regulation in internet addiction disorder and normal students in Ardabil City, in 2014 (Persian)]. Pajouhan Scientific Journal, 14(4), 8-17. [DOI:10.21859/psj-140408]

Rabei, A., \& Mohammadzade, F. (2013). [Virtual space; study of internet using impact on social isolation of university students (Persian)]. Rahbord-e Ejtemai Farhangi, 2(6):43-60.

Russell, D., PePlau, L. A., \& Curtona, C. E. (1980). The Revised UCLA Loneliness scale: Concurrent and discriminate validity evidence. Journal of Personality and Social Psychology. 39(3):47780. [DOI:10.1037/0022-3514.39.3.472]

Satoorian, S. A., Haratian, A., Tahmassian, K., \& Ahmadi, M (2016). The internalizing and externalizing behavioral problems in children: Birth order and age spacing. Developmental psychology: Iranian psychologists, 12(46):173-86.

Sheldon, P. (2008). The relationship between unwillingness-tocommunicate and students' Facebook use. Journal of Media Psychology, 20(2), 67-75. [DOI:10.1027/1864-1105.20.2.67]

Vatani, F., Azadimanesh, P., Poursharifi, H., Osfoori, M. (2015) [Interment addiction and symptoms of attention- deficit hyperactivity disorder in university students (Perisan)]. Journal of Mazandaran University of Medical Sciences, 25(132), 334-7.

Yoo, H. J., Cho, S. C., Ha, J., Yune, S. K., Kim, S. J., Hwang, J., et al. (2004). Attention deficit hyperactivity symptoms and internet addiction. Psychiatry and Clinical Neurosciences, 58(5), 487494. [DOI:10.1111/j.1440-1819.2004.01290.x] [PMID]

Zargar, Y., Bahramabadi, Z., \& Bassak Nagad, S. (2012). [A study of family processes as predictors of behavior problems among second grade high school students in Yasuoj (Persian)]. Jour nal of School Psychology, 1(2), 77-103. 